\title{
Anti-Theft Protection of Vehicle by GSM \& GPS with Fingerprint Verification
}

\author{
Mr. N. Bala Sundara Ganapathy (Assistant Professor), S. Akash, R. Alex Prabhu, T. \\ Kirubakaran, S. Shyam Kumar
}

\begin{abstract}
This paper focuses on preventing car theft using microcontrollers and GSM modules. We are generating the results with better accuracy and proficiency. It can be helpful to those people who want better and more advanced security in their vehicle.
\end{abstract}

Keywords-Arduino Mega, Arduino Nano, Fingerprint, GSM, GPS, Anti Theft, Microcontroller.

\section{INTRODUCTION}

Now a day's automobile burglary cases are increasing day by day, it has gotten to be difficult to give a vehicle an outstanding security with the main focus being kept on the burglary gadget. Vehicle locking framework pledges the best ensure way to secure the vehicle from various types of theft cases. It is a vehicle security gadget that offers a better and fancy insurance to one's vehicle. However this framework cannot be established to give complete security and directness to the vehicle in the event of burglary. [1]So a more secure framework makes the utilization of an inserted framework which is being focused around GSM and GPS innovation. This demarcated and created framework is introduced in the vehicle which aims at providing real time tracking and active notification to user and helps prevent the probable theft.

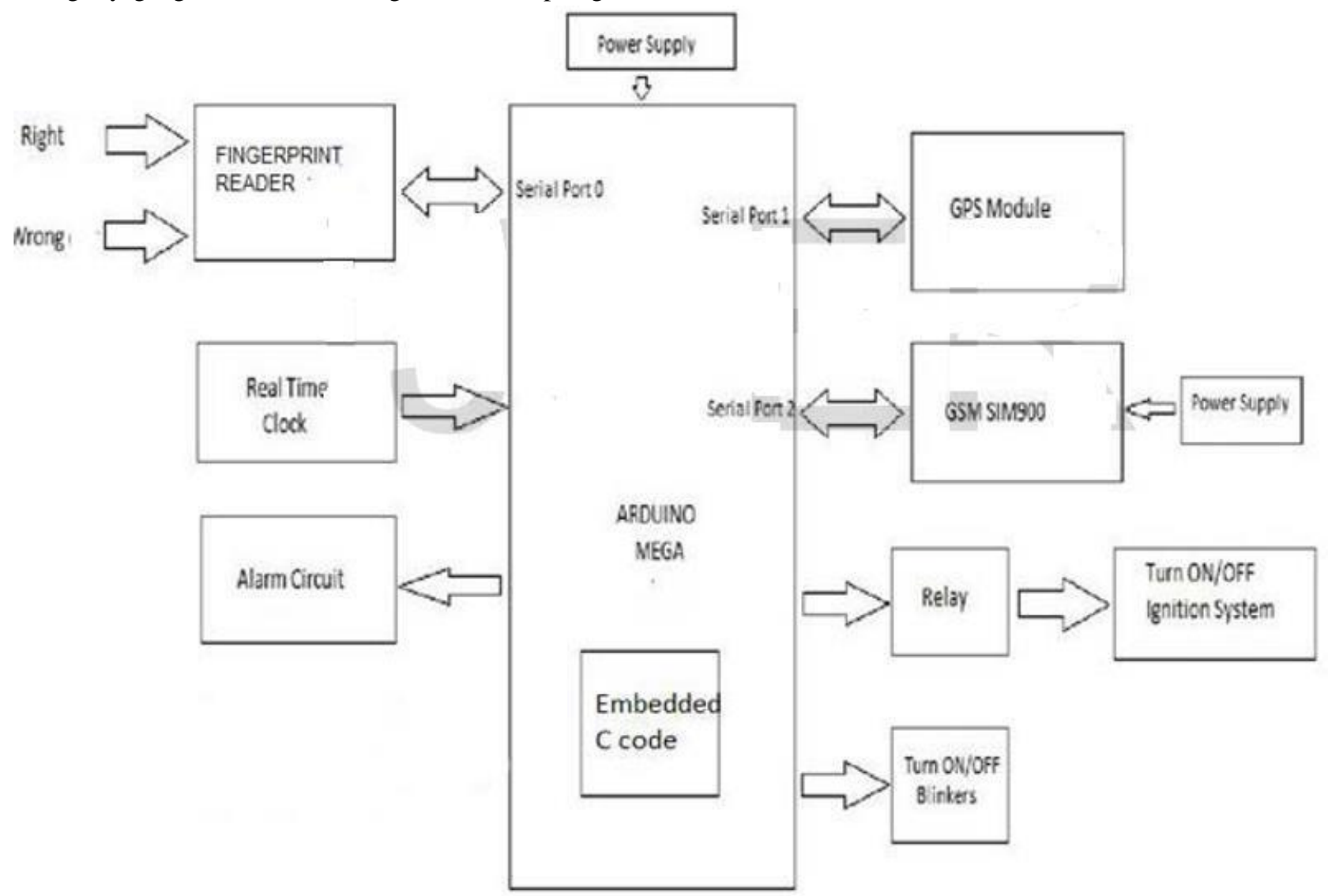

Fig 1: Block Diagram of the Vehicle Ignition System

Passwords are the weakest component of many important security systems, so there is an interrelated push from various directions towards passwords with less friable security measures. While pushing it has some effects, particularly in situation that require more security, it has failed to replace passwords. The vast mainstream of computer user's still use passwords on a routine basis. Since the haven of password relies mostly on user behavior, studies that empirically scrutinize patterns of passwords creation and use the remaining important in the 
assessment of various security policies. The main emphasis while developing this car anti-theft system was to assimilate the above features equally. The most significant feature is the vehicle security from theft and it has been guaranteed by providing certain layers of antitheft protection.

\section{RELATED WORK}

The main aim of this project is to prevent the vehicle from probable theft. To achieve this we are incorporating security by including biometrics, i.e a fingerprint. In the beginning the owner of the vehicle must store his/her own fingerprint in the finger print module. The GSM modem is used to send and receive messages to and from the owner. The owner's mobile number has to be set fixed during the coding. To start the ignition of the fourwheeler one should enter the authorized fingerprint. If anyone enters an unregistered fingerprint, the owner will immediately receive a message and the local alarm system will be turned on. For theft prevention, we can also trace the four-wheeler by giving a call to the GSM modem which is embedded on the system. Then real time tracking begins and the GPS location of the vehicle is sent to the owner by SMS. The ignition of the vehicle can also be controller through notifications to the system. In this proposed project we are using GPS module to find the current latitude and longitude of the present location, the GPS module is UART (Universal Asynchronus Reciever/Transmitter) with a baud rate of 9600 bps. We are using two serial ports. One, for the GSM modem and another one for the GPS modem. The coding is written in embedded $\mathrm{c}$ language and Arduino IDE was used to program it. It is a fitted device on the automobile. The whole monitoring of entire device is done by the mobile phone which delivers wireless connection amongst the vehicle tracking system device and the customer. The vehicle tracking device also has a dedicated sim card slot in which a GSM SIM card is inserted in to receive and send SMS. The user can send an SMS through his mobile phone, know the location of its vehicle and also the facility to safeguard the vehicle. So for the understanding of the whole operation of this vehicle tracking system is distributed in two parts: 1. Tracking the position of vehicle. 2. To provide security to vehicle. The vehicle tracking system consists of a GPS receiver which provides real time position of the automobile. This real time data is deposited in MMC(Main Memory Module) after a set time of intermission by the MCU(Main Control Unit). GSM module is undoubtedly associated with the MCU which is then used to propel and receive the SMS. GSM module takes the information from the MMC and sends this information to the registered user's mobile cell phone. This data consists of longitude, latitude, altitude, the speed over ground, and the course over ground, the real time and date. By using Google maps we can then locate the exact location of vehicle. The vehicle tracking system also has another singular feature which tells not only the whereabouts of vehicle but also securing the automobile. To know the location of the automobile, it is necessary to stop the automobile as soon as possible. For repossessing the automobile, we are using to convey the message in such a way they are allied to the buzzer and other is associated to the power supply of the engine of automobile. User can simply deactivate the engine of automobile by sending a message from his cellphone and we can get the automobile back very soon.

\section{HARDWARE AND SOFTWARE}

\subsection{Hardware the Hardware requirements are as} follows:

\subsubsection{Arduino MEGA 2560 Microcontroller}

The Arduino Mega 2560 microcontroller is an available microcontroller board based on the ATmega2560. It has 54 digital input/output pins out of which 14 can be used as PWM outputs, 16 are analog inputs, 4 are UART's (hardware serial ports), a $16 \mathrm{MHz}$ crystal oscillator, USB connection, power jack, an ICSP header and a reset button. We need to connect it to a computer with a USB cable or power it with a AC-to-DC adapter or battery to get it started. The Mega is compatible with most of the shield designed for the Arduino Duemilanove or Diecimila. The Arduino Mega2560 microcontroller can be powered through the USB connection or with an external power supply. The power supply is selected automatically. External (non-USB) power can be either from an AC-to-DC adapter or a battery. The adapter can be the connected by plugging the plug into the microcontroller board's power jack. Leads from any battery can then be inserted in the pins Gnd and Vin pin headers of the POWER connector of the board. The board can also operate on an external supply voltage of 6 to 20 volts. If it is supplied with less than $7 \mathrm{~V}$, the $5 \mathrm{~V}$ pin may supply less than five volts and then the board may become unstable. If we are using more than $12 \mathrm{~V}$ of voltage, the voltage regulator may get overheated and then damage the board. The recommended range is therefore 7 to 12 volts.

\subsubsection{Arduino Nano Microcontroller}

The Arduino Nano is a very small,a complete, and a breadboard-friendly board based on the ATmega328 orATmega168. It has almost the same functionality of the Arduino Duemilanove, but in a slightly different package. It lacks only a DC power jack, and works with a Mini-B USB cable instead of a standard one. The Nano was designed and is being produced by Gravitech. 


\subsubsection{Fingerprint Sensor R-305}

Fingerprint processing includes two major parts: fingerprint enrolment and fingerprint matching (the matching can be $1: 1$ or $1: \mathrm{N}$ ). While enrolling, the user needs to enter his/her finger two times. The system will process the finger images and then generate a template of the finger based on the processing results and store the corresponding template. While matching, the user enters the finger again through the optical sensor and the system will generate a template of the finger and compare it with available templates of the available finger library. For 1:1 matching, the system will then compare the live finger with the specific template designated in the given Module; for 1:N matching, or searching, the system will then search the whole finger library for the available matching finger. In both such circumstances, the system will then return the matching result, as either success or failure.

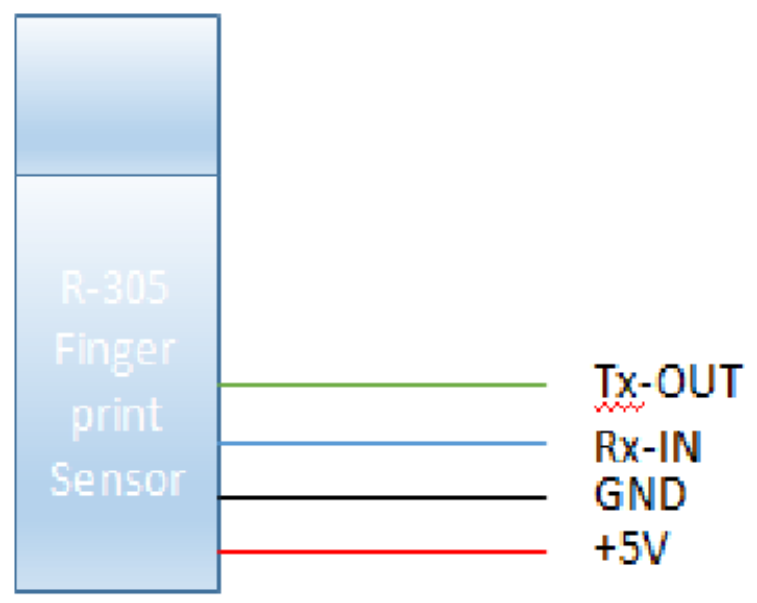

Fig.2: Fingerprint Sensor R-305 3.1.4 GPS Vehicle Tracker

GPS uses the satellite data to calculate an accurate position on the planet earth. The calculations made by GPS can help relate the user's location to almost any map projection within a few milli-seconds. All GPS modules work in an analogous manner but they often look very diverse and have different software. The most noteworthy difference between GPS receivers is the given number of available satellites they can instantaneously communicate with. Most receivers are designated as 12 channel i.e they can interconnect with 12 satellites. Older representations may be 8 or even 5 channel with more modern receivers proficient of communicating with $14-20$.

\subsubsection{GSM Module SIM900A}

The GSM shield by Arduino is used to send or receive messages and make or receive calls just like a mobilephone by using a SIM card of any network provider. We can do this by plugging the GSM shield into the given Arduino board and then plugging in a SIM card from any operator that offers the GPRS coverage. The shield employs the use of a radio modem by the company, SIMComm. We can communicate easily with the shield using the available commands. The GSM library contains the various methods of communication with the shield. [10]This GSM Modem can then work with any GSM network operator SIM card just like an ordinary mobile phone with its own 10 digit unique phone number. The advantage of using this modem is that its RS232 port can be used to interconnect and develop various embedded applications.

Applications like the SMS Control, the data transfer, remote control and logging can be developed easily using this module. The modem can either be connected to the PC serial port directly or to any microcontroller with the help of MAX232. It is used extensively to send/ or receive SMS and make or receive voice calls. It can also be used in the GPRS mode to connect to the internet and then run various applications for data logging and control. In GPRS mode you can also connect to any the remote FTP server and then upload files for the purpose of data logging. It is a highly malleable plug and play quad band SIM900A GSM modem for direct and easy amalgamation to RS232 applications. It supports various features like Voice, SMS, Data/Fax, GPRS and integrated TCP/IP stack. To be connected to any cellular network, the shield primarily requires a SIM card that is provided by a network provider. Most recent revision of the available board makes the connections of the such shield with the Arduino board by connecting its TX to pin 0 of Arduino and pin 1 of Arduino to RX of shield.

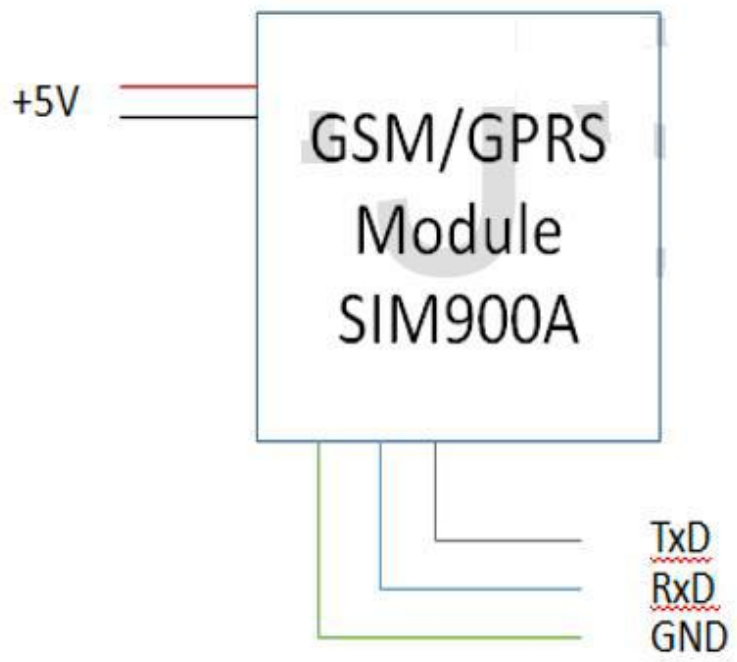

Fig.3: GSM Shield

\subsection{Software the Software requirement is as follows:} 3.2.1 Arduino IDE

Arduino IDE is a GUI based Software that supports all the Arduino based microcontrollers. It is a cross platform application written in the programming language Java. It 
is an open-source Software (IDE) that makes it very easy to write code and also upload it to the board. It runs on various operating systems Windows, Mac OS X and Linux. It originated from the IDE for the languages such as Processing and Wiring. A program written with the IDE for Arduino is called a "sketch". The Arduino IDE supports the languages such as $\mathrm{C}$ and $\mathrm{C}++$ using special rules to organize the code. The Arduino IDE supplies a software library called Wiring from the Wiring project, which provides a lot of common input and output procedures.

\subsubsection{Operating System}

Windows 7 or greater Operating System is required for the Fingerprint Sensor. Windows 10 is preferably the better choice, since it supports all the legacy devices and its drivers.

\section{RESULTS}

A project or system has to be tested under various conditions to ensure its correctness. The testing conditions for this project include several authorized and unauthorized attempts to access the system. These include: - Authorized access i.e., registered fingerprint to access the system. - Unauthorized access i.e. unregistered fingerprint. - Vehicle being dragged for a specific duration. - Notification from the user to activate and deactivate the system. IJSER

Table.1: Result of all the possible I/P's

\begin{tabular}{|l|l|l|}
\hline SCENARIO & INPUT TO SYSTEM & OUTPUT \\
\hline $\begin{array}{l}\text { Authorized } \\
\text { access }\end{array}$ & $\begin{array}{l}\text { Biometric (Registered } \\
\text { Fingerprint) }\end{array}$ & $\begin{array}{l}\text { The ignition is } \\
\text { turned on }\end{array}$ \\
\hline $\begin{array}{l}\text { Unauthorized } \\
\text { Access }\end{array}$ & $\begin{array}{l}\text { Biometric } \\
\text { (Unregistered } \\
\text { Fingerprint) }\end{array}$ & $\begin{array}{l}\text { Local alarm } \\
\text { system } \\
\text { activated and } \\
\text { message sent } \\
\text { to the user }\end{array}$ \\
\hline $\begin{array}{l}\text { Unauthorized } \\
\text { Access }\end{array}$ & $\begin{array}{l}\text { Vehicle } \\
\text { dragged }\end{array}$ & $\begin{array}{l}\text { Local alarm } \\
\text { system } \\
\text { activated and } \\
\text { notification } \\
\text { sent to user. }\end{array}$ \\
\hline Activating RTT & $\begin{array}{l}\text { Call from user to } \\
\text { activate RTT }\end{array}$ & $\begin{array}{l}\text { RTT activated } \\
\text { and } \\
\text { notification } \\
\text { sent to user }\end{array}$ \\
\hline $\begin{array}{l}\text { Deactivating } \\
\text { RTT }\end{array}$ & $\begin{array}{l}\text { Call from user to } \\
\text { deactivate RTT }\end{array}$ & $\begin{array}{l}\text { RTT } \\
\text { deactivated } \\
\text { and } \\
\text { notification } \\
\text { sent to user. }\end{array}$ \\
\hline
\end{tabular}

\section{LIMITATIONS}

Some important limitations are: 1.The mobile network may not always be available and the notification to user may not be delivered in a timely manner. 2.The GPS receiver's connection to the satellites may be hindered and the location information may not be accurate.

\section{CONCLUSION}

The project titled "Smart Anti-Theft Device for Vehicle Security" is a model for an anti-theft device for fourwheelers. The project is aimed at implementing an antitheft device with real time tracking and user control. This is achieved with the help of GPS and GSM technology. The project provides an extra layer of security by including biometrics in the form of fingerprint recognition to grant access to the vehicle. To prevent all possible ways of vehicle theft, a sensor which detects the vehicle being dragged has also been included in the project.

\section{REFERENCES}

[1] El-Medany,W.; Al-Omary,A.; Al-Hakim, R.;AlIrhayim,S.; Nusaif,M.,"A Cost Effective RealTime Tracking System Prototype Using Integrated GPS/GPRS Module," Wireless and Mobile Communications (ICWMC), 2010 6th International Conference on,vol.,no.,pp.521,525,20-25 Sept.2010 International Journal of Computer Science, Engineering and Applications (IJCSEA) Vol.3, No.3, June 2013

[2] Hu Jian-ming; Li Jie; Li Guang-Hui, "Automobile Anti-theft System Based on GSM and GPS Module," Intelligent Networks and Intelligent Systems (ICINIS), 2012 Fifth International Conference on , vol., no., pp.199,201, 1-3 Nov. 2012

[3] P. Fleischer, A. Nelson, R. Sowah and A. Bremang, "Design and development of GPS/GSM based vehicle tracking and alert system for commercial inter-city buses," IEEE 4th International Conference on Adaptive Science \& Technology (ICAST), October 2012

[4] T. Le-Tien and V. Phung-The, "Routing and Tracking System for Mobile Vehicles in Large Area,"

[5] P. Verma and J. Bhatia, "Design and Development of GPS-GSM based Tracking System with Googlemap based Monitoring," International Journal of Computer Science, Engineering and Applications (IJCSEA), vol. 3, no. 2, June 2013 